\title{
Emerging Haemosporidian Infections in Village Chickens (Gallus gallus domesticus) in Yobe State, Nigeria
}

\author{
Jallailudeen Rabana Lawal ${ }^{1, ~ *, ~ U m a r ~ I s a ~ I b r a h i m ~}{ }^{1}$, Abdullahi Abubakar Biu², Kasim Muhammed ${ }^{3}$ \\ ${ }^{1}$ Department of Veterinary Medicine, Faculty of Veterinary Medicine, University of Maiduguri, Maiduguri, Nigeria \\ ${ }^{2}$ Department of Veterinary Parasitology and Entomology, Faculty of Veterinary Medicine, University of Maiduguri, Maiduguri, Nigeria \\ ${ }^{3}$ Area Veterinary Clinic (Zone A), Ministry of Agriculture and Natural Resources, Damaturu, Nigeria
}

Email address:

rabanajallailudeen@yahoo.com (J. R. Lawal)

${ }^{*}$ Corresponding author

To cite this article:

Jallailudeen Rabana Lawal, Umar Isa Ibrahim, Abdullahi Abubakar Biu, Kasim Muhammed. Emerging Haemosporidian Infections in Village Chickens (Gallus gallus domesticus) in Yobe State, Nigeria. American Journal of Biomedical and Life Sciences.

Vol. 9, No. 4, 2021, pp. 190-196. doi: 10.11648/j.ajbls.20210904.13

Received: June 21, 2021; Accepted: July 12, 2021; Published: August 27, 2021

\begin{abstract}
In some parts of Nigeria, studies have revealed avian haemosporidian infections in village chickens, some of which are considered emerging parasitic infections because chickens are unnatural hosts. Infections may have occurred as a result of accidental cross-infection via infected haemophagus arthropod vectors. This study was carried out to determine the emerging avian haemosporidian infections in Village chickens in Yobe State, Nigeria using microscopy. Blood samples were collected from 2100 Village chickens in 7 Local Government Areas of Yobe State. Microscopy revealed an overall prevalence of 13.8\% (290/2100) for avian haemosporidians comprising of Plasmodium with 13.9\% (198/2100) and Haemoproteus $2.4 \%$ (55/2100) as single infections. Mixed infection of Plasmodium and Haemoproteus had a prevalence of $1.8 \%$ (37/1820). Male (9.9\%) had a higher prevalence of avian haemosporidian infections than female chickens (4.0\%). Adults (10.4\%) had a higher prevalence than growers chickens $(3.4 \%)$, and prevalence was higher in the rainy $(9.3 \%)$ than the dry $(4.5 \%)$ season of the study period. Detection of Haemoproteus specie in chickens in Yobe State is considered an emergent infection because chickens are not natural host to the parasite. It is therefore recommended that Village chicken producers should be educated on the risk factors and impacts of avian haemosporidian on bird productivity through frequent agricultural extension services. More research is needed to assess the frequency of avian haemosporidian infections in other poultry species in Nigeria, in order to better understand the disease's epidemiology and develop effective management and prevention strategies.
\end{abstract}

Keywords: Emerging Infection, Village Chickens, Avian Haemosporidian, Yobe State, Nigeria

\section{Introduction}

Poultry is raised by a large number of rural people around the world, and it serves an important economic role in delivering rich animal protein (meat and eggs) and alleviating poverty [28]. Small-scale chicken production operations in impoverished nations involve breeding a few birds that are not provided with contemporary housing facilities for roosting at night, scavenge around households, receive no medical attention, and are not routinely vaccinated [38].

Infectious poultry diseases such as viral, bacterial, protozoan, and parasitic diseases are a major barrier to a successful village chicken production system in developing countries [7, 15, 36, 43], but avian haemosporidian infections and their consequences in village chickens have received little attention. Village chickens are typically reared under the extensive management systems in most parts of Nigeria [26]. They have access to the environment where they scavenge for food even on unhygienic garbage dumps and near unhygienic pool of water [2]. Village chickens are more likely to be subjected to bites from many types of haemophagus arthropod vectors that may host blood parasites compared to chickens raised in screened pens or restricted to intensive management systems [15, 17, 35]. Although several published research has identified blood parasites primarily in wild and other birds in tropical areas worldwide, recent studies have found emerging haemoparasite infections in 
poultry species including village chickens [1, 27, 39]. Plasmodium, Leucocytozoon, Haemoproteus, Microfilaria, Aegyptinella, Fallisia and Trypanosoma species are genera of haemoparasites recorded in chickens around the world $[3,6$, 41]. Avian haemosporidian is an emerging parasite infection in domesticated birds, and there has been an increase in research revealing avian haemosporidian infections in domesticated birds in some parts of Nigeria [9, 14, 25, [27], raising concerns. However, because there is no published data on the prevalence of avian haemosporidian infections in village chickens in Yobe State, Nigeria, a study on the prevalence of haemosporidian infections in village chickens is needed to develop strategies for effective control programs and to improve the safety and productivity of village chickens in the study area.

\section{Materials and Methods}

\subsection{Study Area}

Yobe State is located in northeastern Nigeria, with Damaturu as its capital and Potiskum (Figure 1) as its main city. The state shares borders with four states: Bauchi, Borno, Gombe, and Jigawa, as well as the Diffa and Zinder regions of Niger to the north. Because the state is primarily located in the dry savanna zone, the climate is hot and dry for the majority of the year.

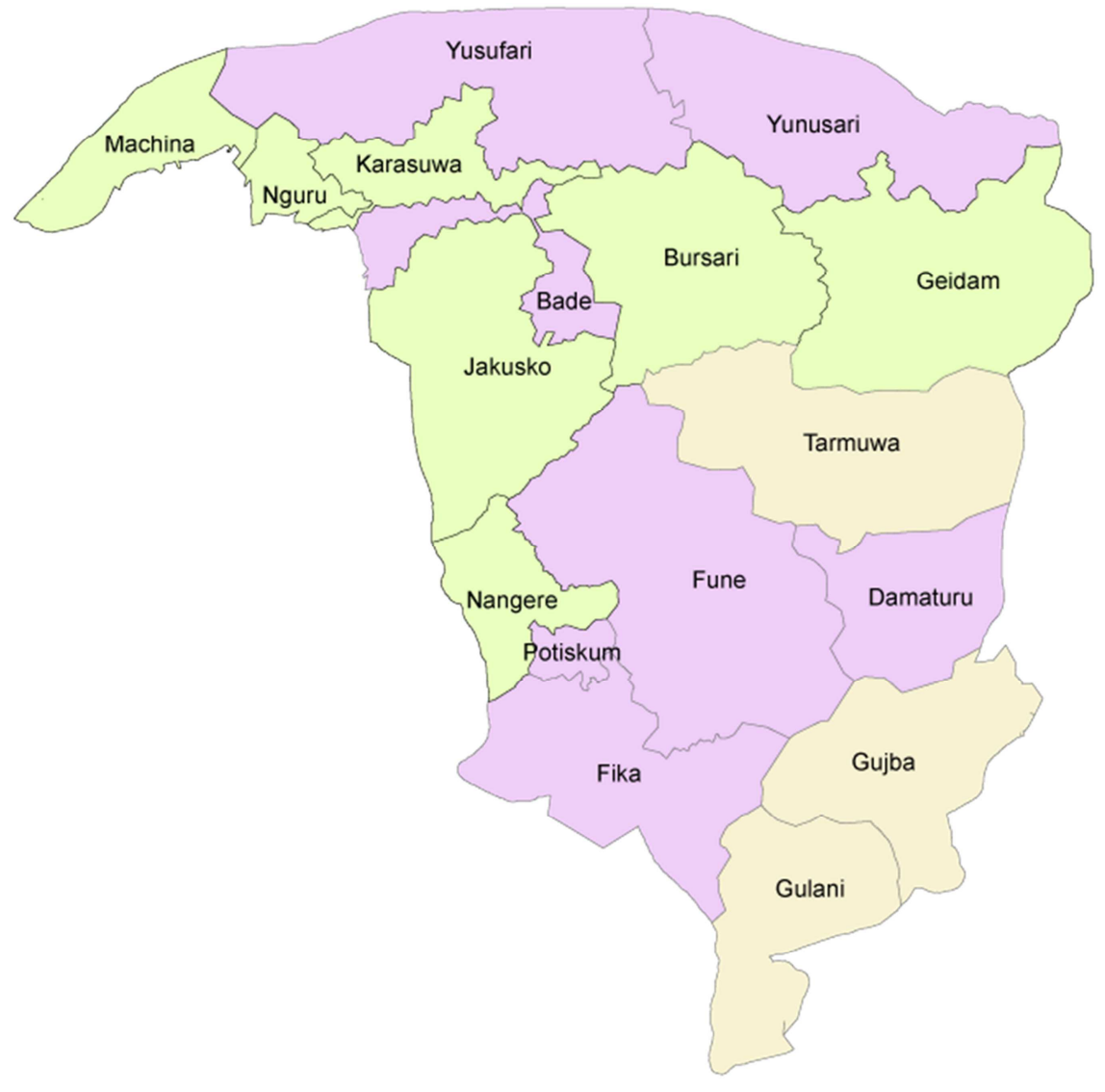

Figure 1. Map of Yobe State showing the study areas.

\subsection{Study Design and Study Population}

After getting consent from their owners, a total of 2100 village chickens were sampled from families that rear several poultry species as part of a cross-sectional study that used non-probability sampling procedures.

\subsection{Study Period and Blood Sample Collection}

Blood samples and other data collections were carried out from September 2019 to November 2020. Blood samples were aseptically collected from each sampled village chicken via the wing vein (venipuncture) using sterile $5 \mathrm{ml}$ syringes and 23 gauge needles. Blood samples were immediately dispensed into sample bottles containing EDTA as anticoagulant and transported in cool flasks to the Department of Veterinary Parasitology and Entomology Research laboratory for processing and microscopy examination.

\subsection{Blood Smear Preparation}

Thin blood and buffy coat smears were made on a clean dry slide according to standard protocol as described by Mello et al. [18], smears were allowed to air dry for a few minutes, then fixed in absolute methanol, and then allowed to air dry again, before properly labeling each slide. 


\subsection{Microscopic Detection of Avian Haemosporidian}

The slides were stained with Giemsa stain ( $\mathrm{pH} 7.2$ ), raised with distilled water, and allowed to air dry according to the standard procedures described by Ribeiro et al. [31]. Stained blood smears were later viewed under a light Olympus ${ }^{\circledR}$ (Japan) microscope first at low magnification (40x), and then at high magnification (100x) oil immersion objective for the presence of intracellular or extracellular blood parasites. The haemosporidian schizonts, gametocytes, and trophozoites were examined and identified based on morphology as previously described by Valkiûnas [41].

\subsection{Data Analysis}

GraphPad Prism software (GraphPad Inc., San Diego, CA) was used to analyze the data. Prevalence rates were calculated as percentages of proportions, the Chi-squared test was used to compare categorical variables (age, sex, and season), and the relative risk calculated using the GraphPad Prism software. The lower and upper limits of the $95 \%$ confidence interval for a proportion were calculated using the procedures provided by Newcombe [22]. Differences were considered significant for $p$-values equal to or less than 0.05 .

\section{Results}

The prevalence of Haemosporidian infections in village chickens from Yobe State, Nigeria, is summarized in Table 1. Out of the total 2100 village chickens sampled and examined, haemosporidian infections were found in 290 chickens with an overall prevalence rate of $13.8 \%$ (95\% Confidence interval $=12.4 \%-15.4 \%)$. The prevalence rate in Damaturu $(2.7 \%$; $95 \%$ Confidence interval $=2.1 \%-3.5 \%)$ was found to be higher followed by Postikum $(2.3 \% ; 95 \%$ Confidence interval $=1.8 \%-3.1 \%)$, Fika $(2.1 \% ; \quad 95 \% \quad$ Confidence interval $=1.5 \%-2.8 \%)$, Bade $\quad(1.8 \% ; \quad 95 \% \quad$ Confidence interval $=1.3 \%-2.5 \%)$, Yunusari $(1.8 \% ; 95 \%$ Confidence interval $=1.3 \%-2.5 \%), \quad$ Fune $\quad(1.7 \% ; \quad 95 \% \quad$ Confidence interval $=1.2 \%-2.3 \%)$ and Yusufari $(1.4 \% ; 95 \%$ Confidence interval $=1.0 \%-2.0 \%$ ) Local Government Areas of the study area.

The emerging haemosporidian infections in Village Chickens in Yobe State, Nigeria are summarized in Table 2. The prevalence of Plasmodium spp. infection $(9.4 \%$; $95 \%$ Confidence interval $=8.3 \%-10.8 \%$ ) is higher compared to Haemoproteus spp. infection $(2.6 \%$; 95\% Confidence interval $=2.0 \%-3.4 \%$ ). Thus Plasmodium spp. and Haemoproteus spp. mixed infections (1.8\%; 95\% Confidence interval $=1.3 \%-2.4 \%$ ) were found to be the least prevalent in this study period.

Table 3 summarizes the results of some risk factors associated with haemosporidian infections in Village Chickens in Yobe State, Nigeria. The prevalence of haemosporidian infections in males $(9.9 \%$; $95 \%$ Confidence interval $=8.7 \%-11.2 \%$ ) was found to be higher than in female (4.0\%; 95\% Confidence interval $=3.2 \%-4.9 \%)$ chickens, and the association between the prevalence of haemosporidian infections and chicken age was shown to be statistically significant $\left(p<0.0001 ; \chi^{2}=75.052 ;\right.$ Relative risk=2.743). However, the prevalence of haemosporidian infections was found to be higher in adults $(10.4 \%$; $95 \%$ Confidence interval $=9.2 \%-11.8 \%)$ compared to growers $(3.4 \% ; 95 \%$ Confidence interval $=2.7 \%-4.2 \%$ ) chickens, and the association between the prevalence of haemosporidian infections and age group of chickens was also found to be statistically significant $\left(p<0.0001 ; \quad \chi^{2}=39.211 ;\right.$ Relative risk $=3.881$ ). The prevalence of haemosporidian infections in the rainy $(9.3 \% ; 95 \%$ Confidence interval $=8.1 \%-10.6 \%)$ was found to be higher compared to the dry $(4.5 \% ; 95 \%$ Confidence interval $=3.7 \%-5.5 \%$ ) season of the sampling period; and the association between the prevalence of haemosporidian infections and sampling season was also found to be statistically significant $\left(p<0.0001 ; \chi^{2}=39.211\right.$; Relative risk=2.053).

Table 1. Haemosporidian infections in Village Chickens from Yobe State, Nigeria.

\begin{tabular}{lllll}
\hline Study areas & No. of chickens examined & No. $(\%)$ of chickens infected & Prevalence (\%) \\
\hline Bade & 300 & $38(12.7)$ & 1.8 & 95\% CI LL-UL \\
Damaturu & 300 & $57(19.0)$ & 2.7 & $1.3-2.5$ \\
Fika & 300 & $43(14.3)$ & 2.1 & $1.1-3.5$ \\
Fune & 300 & $35(11.7)$ & 2.3 & $1.5-2.8$ \\
Potiskum & 300 & $49(16.3)$ & 1.8 & $1.2-2.3$ \\
Yunusari & 300 & $38(12.7)$ & 1.4 & $1.8-3.1$ \\
Yusufari & 300 & $30(10.0)$ & 13.8 & $1.3-2.5$ \\
Overall & 2100 & $290(13.8)$ & $1.0-2.0$ \\
\hline
\end{tabular}

Key: LL=Lower limit; UL=Upper limit; $\mathrm{CI}=$ Confidence Interval

Table 2. Emerging Haemosporidian infections in Village Chickens in Yobe State, Nigeria.

\begin{tabular}{|c|c|c|c|c|}
\hline Type of Infection & Haemosporidians Encountered & No. of chickens infected $N=2100$ & Prevalence (\%) & 95\% CI LL-UL \\
\hline \multirow{2}{*}{ Single } & Haemoproteus spp. & 55 & 2.6 & $2.0-3.4$ \\
\hline & Plasmodium spp. & 198 & 9.4 & $8.3-10.8$ \\
\hline Mixed & Plasmodium + Haemoproteus spp. & 37 & 1.8 & $1.3-2.4$ \\
\hline Overall & & 290 & 13.8 & $12.4-15.4$ \\
\hline
\end{tabular}

Key: $\mathrm{N}=$ Total number of chickens examined; $\mathrm{LL}=$ Lower limit; $\mathrm{UL}=\mathrm{Upper}$ limit;

$\mathrm{CI}=$ Confidence Interval 
Table 3. Some Risk factors associated with Haemosporidian infections in Village Chickens in Yobe State, Nigeria.

\begin{tabular}{|c|c|c|c|c|c|c|}
\hline Risk factors & $\begin{array}{l}\text { No. of chickens } \\
\text { examined }\end{array}$ & $\begin{array}{l}\text { No. of chickens infected } \\
(\%)\end{array}$ & $\begin{array}{l}\text { Prevalence (\%) 95\% CI } \\
(\mathrm{LL}-\mathrm{UL})\end{array}$ & $p$-value & $\chi^{2}$ & Relative Risk \\
\hline \multicolumn{7}{|l|}{ Sex } \\
\hline Male & 1000 & $207(20.7)$ & $9.9^{\mathrm{a}}(8.7-11.2)$ & $<0.0001$ & 75.052 & 2.743 \\
\hline Female & 1100 & $83(7.5)$ & $4.0^{\mathrm{b}}(3.2-4.9)$ & & & \\
\hline \multicolumn{7}{|l|}{ Age (months) } \\
\hline Adults $(>5)$ & 930 & $219(23.5)$ & $10.4^{\mathrm{a}}(9.2-11.8)$ & $<0.0001$ & 131.55 & 3.881 \\
\hline Grower $(3-4)$ & 1170 & $71(6.1)$ & $3.4^{\mathrm{b}}(2.7-4.2)$ & & & \\
\hline \multicolumn{7}{|l|}{ Season } \\
\hline Rainy & 1050 & $195(18.6)$ & $9.3^{\mathrm{a}}(8.1-10.6)$ & $<0.0001$ & 39.211 & 2.053 \\
\hline Dry & 1050 & $95(9.0)$ & $4.5^{\mathrm{b}}(3.7-5.5)$ & & & \\
\hline
\end{tabular}

NB: Values with different superscripts ${ }^{\text {a,b }}$ are significantly $(p<0.05)$ different

Key: LL=Lower limit; UL=Upper limit; $\mathrm{CI}=$ Confidence Interval; $\chi^{2}=$ Chi-square

\section{Discussion}

The present study showed $13.8 \%$ overall prevalence of haemosporidian infections in village chickens from Yobe State, Nigeria. This is the first recorded avian haemosporidian prevalence in the study area which makes it an emergent infection in the poultry sector in this part of Nigeria. Our result exceeds that of George et al. [5], who found $2.4 \%$ in Zaria, Kaduna State; Usmana et al. [40], who found $12.0 \%$ in Sokoto; and Igbokwe et al. [11], who found $11.4 \%$ in Maiduguri, Borno State. The present study's findings, however, are lower than the $26.4 \%$ recorded in Ibadan, Oyo State [33], 19.56\% in Kano, Kano State [13], 46.7\% in Owerri, Imo State [27], 37.7\% in Nassarawa States [9], and $23.2 \%$ in Makurdi, Benue State [25]. The disparities in reported prevalence rates of haemosporidian infections in village chickens from various studies could be attributable to sample sizes, geographical locations, as well as the availability of arthropod vectors and season, which could influence vector breeding. Furthermore, higher prevalence rates of avian haemoparasites in village chickens have been documented in some parts of Africa, including $43.4 \%$ in Ethiopia [4], $79.2 \%$ in Kenya [32], $71.0 \%$ and $79.1 \%$ in Malawi by Njunga [23] and Lutz et al. [16] respectively, $61.9 \%$ in Uganda [42], $35.0 \%$ in Ghana [30], 32.0\% in Zimbabwe [29]. These studies demonstrated an increasing evidence of avian haemosporidian in scavenging village chickens from diverse locations of Africa.

The high prevalence of avian haemosporidian recorded in village chickens in Damaturu, Potiskum, and Fika Local Government Areas could indicate that these LGAs have an abundance of arthropod vectors capable of transferring haemosporidian infections to village chickens. These LGAs are the state's largest urban center, with an abundance of poor drainage and open sewers that could create an ideal environment for the reproduction of various arthropods, particularly mosquitoes. Moreover, village chickens' vulnerability to haemosporidian infections in these areas may also be exacerbated by their scavenging habit.

Two haemosporidian taxa, Plasmodium and Haemoproteus, were found to be prevalent in this study, indicating the availability of their appropriate vectors in the studied area.
Gimba et al. [6], Nakayima et al. [19] and Nourani et al. [24] have all reported these two avian haemosporidians, indicating that they are the most common in village chickens and have a global distribution. The present study also discovered mixed Plasmodium and Haemoproteus infections, which is consistent with previous findings $[6,10,16,20,21,25]$. Microfilaria, Leucocytozoon, Aegyptianella, and Trypanosoma were not found microscopically in any of the samples examined in this study, despite reports by Etisa et al. [4] and Opara et al. [27] that these avian haemosporidian and haemoparasites were found in village chickens.

Plasmodium species $(9.4 \%)$ was the most common haemosporidian in village hens, confirming the findings of other researchers who found Plasmodium species to be the most common haemosporidian infection in scavenging birds [4, 6, 8, 19, 21, 32, 37]. However, the Plasmodium prevalence rate in this study is lower than $11.4 \%$ in Maiduguri [11], 12.0\% in Sokoto [40], 33.3\% in Owerri [27], and $32.0 \%$ in Ibadan [33] of Borno, Sokoto, Imo, and Oyo States respective in Nigeria. Variations in reported prevalence rates of avian haemosporidian infections in Nigerian village chickens could be related to variances in management and husbandry practices, as well as the availability of appropriate vectors, environmental and climatic conditions.

The prevalence of a single Haemoproteus infection was found to be $2.6 \%$ in this Study. However, Sabuni et al. [31], Gimba et al. [6], and Nath and Bhuiyan [21] from Ethiopia, Selangor, and Bangladesh, respectively, reported lower prevalence rates of $0.9 \%, 0.8 \%$, and $2.5 \%$. The prevalence of Haemoproteus in village chickens reported in this present study is lower than $23.3 \%$ reported in Bangladesh [12], $13.2 \%$ in Iraq [10] and $50.9 \%$ in Nigeria [14]. This could be due to variances in geographical regions, arthropod vector abundance, and season of sample collection. Village chickens have been reported as an unnatural host to Haemoproteus specie, which has been frequently detected in pigeons and other wild birds. Infection of the chickens by Haemoproteus specie may occur during a blood meal where suitable vectors may visit both host and result in cross-infection from pigeon to chicken, which are commonly reared together in households. In some infected village chickens, a mixed Plasmodium and 
Haemoproteus species infection was discovered at a prevalence rate of $1.8 \%$. This study agrees with the findings of Naqvi et al. [20], who found mixed Plasmodium and Haemoproteus species infection in scavenging chickens. However, our finding is lower than $47.4 \%$ reported by Hasson [10], but higher than $0.5 \%$ reported by Nath and Bhuiyan [21].

The results of this study revealed a higher prevalence in males $(9.9 \%)$ than female $(4.0 \%)$ village chickens which was statistically significant $(p<0.0001)$, and this could be attributed to the facts that cocks anatomically have larger combs and wattles, that are richly supplied with blood vessels which may attract blood sucking arthropods that transmit haemosporidians to the host bird. Previous studies [14, 25, 27] have found that male have a greater prevalence of avian haemosporidians than female village chickens in some parts of Nigeria. The findings of our study are also in line with previous reports in Africa and Asia [4, 8, 32]. It is important to note that other worker have reported higher prevalence of haemoparasites in the hen $[10,20,21,34]$.

The prevalence of avian haemosporidian infections based on age of village chickens in this study has revealed a higher prevalence in adults (10.4\%) compared to the growers $(3.4 \%)$ which was statistically significant $(p<0.0001)$. This might be attributed to the behaviour of adult village chickens which roam far long distance to scavenge for food on or near unhygienic environments and travel far in search of mates, and this predisposes them to higher risks of contact with arthropods vectors, while the growers are usually found near their roosting areas. Also, adult chickens have more prominent and developed combs and wattles which are well vascularized and provide predilection sites for arthropods vectors. This finding concurs with the findings of Abdul Momin et al. [1] in Bangladesh and Etisa et al. [4] in Ethiopia who also reported significantly $(p<0.05)$ higher prevalence of haemoparasites infection in adult chickens compared to growers. However, this finding contradicts that of Sabuni et al. [32] in Kenya and Naqvi et al. [20] in Pakistan who reported a relatively higher prevalence of avian haemosporidian infections in growers compared to adult chickens, but the difference was not statistically significant $(p>0.05)$.

This present study has revealed a significantly $(p<0.0001)$ higher prevalence of haemoparasites during the rainy season $(9.3 \%)$, which is the season that provides favourable conditions such as temperature and humidity that allow breeding of most arthropod vectors such as mosquitoes and other biting flies. The prevalence recorded in this study agrees with the findings of Igbokwe et al. [11] who also reported a high prevalence of avian haemoparasites during the rainy season in Maiduguri, Nigeria, but contrasted with Nath and Bhuiyan [21] who reported higher prevalence of haemoparasites in dry season.

\section{Conclusion and Recommendations}

In Yobe State, Haemosporidian parasites of Village chickens such as Plasmodium and Haemoproteus species are prevalent $(13.8 \% ; 95 \% \quad \mathrm{CI}=12.4 \%-15.4 \%)$. The prevalence of haemosporidian infections were significantly higher in male, adults chickens and higher in the rainy season of the study period. Plasmodium (9.4\%) was discovered to be the most prevalent haemosporidian in village hens in Yobe State, and Haemoproteus species discovery in chickens is considered an emerging infection because chickens are not Haemoproteus species' native hosts. Village chicken farmers should be educated about the risk factors and effects of haemosporidian infection on bird productivity by regular extension services, with an emphasis on control and prevention methods. To better understand the epidemiology of the disease, more research should be done to assess the prevalence of avian haemosporidian in other avian species in the study area. To characterize the Haemosporidian species infecting village chickens in Yobe State, more advanced molecular approaches should be used.

\section{Conflicts of Interest}

The authors declare that they have no competing interests.

\section{Acknowledgements}

The authors would like to express their gratitude to the staff of the Department of Veterinary Parasitology and Entomology Research Laboratories, Faculty of Veterinary Medicine, University of Maiduguri, for their technical assistance during sample analysis, as well as the Area Veterinary Officers and staff of the State Veterinary Clinic (Zone A), Damaturu, Yobe State, for their assistance during the sample collection period.

\section{References}

[1] Abdul Momin, M. A., Begum, N., Dey, A. R., Paran, M. S. and Alam, M. Z. (2014). Prevalence of Blood Protozoa in Poultry in Tangail, Bangladesh. Scholars Journal of Agriculture and Veterinary Science 7 (7): 55-60.

[2] Chepkemoi M, Macharia J W, Sila D, Oyier P, Malaki P, Ndiema E, Agwanda B, Obanda V, Ngeiywa K J, Lichoti J and Ommeh S C (2017). Physical Characteristics and Nutritional Composition of Meat and Eggs of five Poultry species in Kenya. Livestock Research for Rural Development. Volume 29, Article \#153.

[3] Dimitrov, D., Zehtindjiev P., Bensch, S., Ilieva, M., Iezhova, T. and Valkiûnas, G. (2014). Two New species of Haemoproteus Kruse, 1890 (Haemosporida, Haemoproteidae) from European Birds, with emphasis on DNA barcoding for Detection of Haemosporidians in Wildlife. Systematic Parasitology, 87: 135-151.

[4] Etisa, E., Chanie, M. and Tolossa, Y. H. (2017). Prevalence of Haemoparasites Infections in Scavenging Indigenous Chickens in and around Bishoftu. World Applied Sciences Journal, 35 (2): 302-309. 
[5] George, B. D. J., Saidu, L. and Abdu, P. A. (2004). A Review and Case Reports of Parasitic Arthropods infesting Local Poultry and their Roles in the Transmission of Haemoparasites in Nigeria. Tropropica Veterinaria. 22, (2): 61-67.

[6] Gimba, F. I., Zakaria, A., Mugok, L. B., Siong, H. C., Jaafar, N., Moktar, M., A., Rahman, A. R. A., Amzah, A., Abu, J., Sani, R. A., Amin-babjee., S. M. and Reuben, S. K. S. (2014). Haemoparasites of Domestic Poultry and Wild Birds in Selangor, Malaysia. Malaysian Journal of Veterinary Research, 5 (1): 43-51.

[7] Hamer, G. L., Anderson, T. K., Berry, G. E., Makohon-Moore, A. P., Crafton, J. C., Brawn, J. D., Dolinski, A. C., Krebs, B. L., Ruiz, M. O., Muzzall, P. M., Goldberg, T. L. and Walker, E. D. (2013). Prevalence of Filarioid Nematodes and Trypanosomes in American Robins and House Sparrows in Chicago. International Journal of Parasitology: Parasites and Wildlife, 2: 42-49.

[8] Hasan, A. M., Hossain, M. S., Anita Rani Dey, A. R. and Alam, M. Z. (2017). Prevalence of Malaria Parasites in Indigenous Chickens and Ducks in Selected Districts of Bangladesh. Journal of Bangladesh Agricultural University, 15 (2): 260-265.

[9] Hassan, D. I., Faith, E. A., Yusuf, N. D., Azaku, E. A and Mohammed J. (2018). Haemosporidians of village chickens in the southern ecological zone of Nassarawa state, Nigeria. Nigerian Journal of Animal Science and Technology, 1 (2): 29-37.

[10] Hasson, R. H. (2015). Haemosporidians Parasites of Gallus domesticus, Poultry in Iraq. International Journal of Advanced Research, 3 (8): 1046-1054.

[11] Igbokwe, I. O., Hassan, S. U.., Faive, Z. T., Iliya, Y., Dagare, M. J., Rabo, J. S., Mohammed, A. and Igbokwe, N. A. (2008). Effect of Plasmodium species infections on Packed Cell Volume of Domestic Chickens and Helmeted Guinea Fowls in Northeastern Nigeria. Animal Research International, 5 (3): 892-895.

[12] Islam, A., Anisuzzaman, Rabbi, A. K. M. A., Rahman, A., Islam, M. A. and Rahman, M. H. (2013). Haemoproteus species Infection of Domestic Poultry of Bangladesh. VETSCAN, 7 (2): 85-88.

[13] Karamba, K. I., Kawo, A. H., Dabo, N. T and Mukhtar, M. D. (2012). A Survey of Avian Malaria Parasite in Kano State, Northern Nigeria. International Journal for Biotechnology and Molecular Biology Research, 3 (1): 8-14.

[14] Lawal, J. R., Bello, A. M., Balami, S. Y., Dauda, J., Malgwi, K. D., Ezema, K. U., Kasim, M. and Biu, A. A. (2016). Prevalence of Haemoparasites in Village Chickens (Gallus gallus domesticus) Slaughtered at Poultry Markets in Maiduguri, Northeastern Nigeria. Journal of Animal Science and Veterinary Medicine, 1:39-45.

[15] Letebrhan G, Aberra M, Sandip B and Gebremedhn B (2015). Product Utilization, Constraints and Opportunities of Village Chicken under Traditional Management System in Gantaafeshum District of Eastern Tigray, Ethiopia. Journal of Natural Sciences Research, 5 (11): 33-38.

[16] Lutz, H. L., Hochachka, W. M., Engel, J. I., Bell, J. A., Tkach, V. V., Bates, J. M., Hackett, S. J. and Weckstein, J. D. (2015). Parasite Prevalence corresponds to Host Life History in a Diverse Assemblage of Afrotropical Birds and Haemosporidian. PLoS One 10 (4): 1371.

[17] Malatji, D. P., Tsotetsi, A. M., Van Marle-Koster, E. and
Muchadeyi, F. C. (2016). A Description of Village Chicken Production Systems and Prevalence of Gastrointestinal Parasites: Case studies in Limpopo and KwaZulu-Natal Provinces of South Africa, Onderstepoort Journal of Veterinary Research, 83 (1): 968.

[18] Mello, M. B. C., Luz, F. C., Leal-Santos, F. A., Alves Jr, E. R., Gasquez, T. M. and Fontes, C. J. F. (2014). Standardization of Blood smears prepared in transparent acetate: An alternative Method for the Microscopic Diagnosis of Malaria. Malaria Journal, 13: 238 .

[19] Nakayima, J., Arinaitwe, E., Kabasa, W. M., Kasaija, P. D., Agbemelo-Tsomafo, C. and Omotoriogun, T. C. (2019). Phylogeny and Prevalence of Haemosporidian Parasites of Free-ranging Domestic Birds in Northwestern Uganda. International Journal of Livestock Research, 9 (12): 244-258.

[20] Naqvi, M. A., Khan, M. K., Iqbal, Z., Rizwan, H. M., Khan, M. N., Naqvi, S. Z., Zafar, A., Sindhu, Z. U. D., Abbas, R. Z. and Abbas, A. (2017). Prevalence and Associated Risk factors of Haemoparasites, and their Effects on Haematological Profile in Domesticated Chickens in District Layyah, Punjab, Pakistan. Preventive Veterinary Medicine, 1; (143): 49-53.

[21] Nath, T. C and Bhuiyan, M. J. U. (2017). Haemoprotozoa infection of Domestic Birds in Hilly Areas of Bangladesh. Independent Journal Management and Production, 8: 82.

[22] Newcombe, R. G. (1998). Two-Sided confidence intervals for the Single Proportion: Comparison of Seven Methods. Statistics in Medicine, 17: 857-872.

[23] Njunga, G. R. (2003). Ecto- and Haemoparasites of Chicken in Malawi with emphasis on the Effects of the Chicken louse, Menacanthus cornutus. MSc Dissertation, Department of Veterinary Microbiology and Network for Smallholder Poultry Development, The Royal Veterinary and Agriculture University, Dyrlogevej, Frederiksberg C., Denmark, pp. 1-21.

[24] Nourani, L., Aliabadian, M., Dinparast Djadid, N. and Mirshamsi, O. (2018). Occurrence of Haemoproteus spp. (Haemosporida: Haemoproteidae) in New Host Records of Passerine Birds from the East of Iran. Iranian Journal of Parasitology, 13 (2): 267-274.

[25] Ogbaje, C. I., Jerry A. Okpe, J. A. and Oke, P (2019). Haemoparasites and Haematological Parameters of Nigerian Indigenous (local) and Exotic (broiler) Chickens Slaughtered in Makurdi Major Markets, Benue State, Nigeria. Alexandria Journal of Veterinary Sciences, 63 (2): 90-96.

[26] Opara, M. N., Osowa, D. K. and Maxwell, J. A. (2014). Blood and Gastrointestinal Parasites of Chickens and Turkeys Reared in the Tropical Rainforest Zone of Southeastern Nigeria. Open Journal of Veterinary Medicine, 4: 308-313.

[27] Opara, N. M., Okereke, E. R., Olayemi, O. D. and Jegede, O. C. (2016). Haemoparasitism of Local and Exotic Chickens Reared in the Tropical Rainforest Zone of Owerri Nigeria. Alexandria Journal of Veterinary Sciences, 51 (1): 84-89.

[28] Otte, J. (2006). The Hen which Lays the Golden Eggs - or why Backyard Poultry are so Popular (http://www.fao.org/ag/againfo/programmes/en/pplpi/docarc/f eature01_backyardpoultry.pdf, accessed April 2018).

[29] Permin, A., Esmann, J. B., Hoj, C. H., Hove, T. and Mukatirwa, S. (2002). Ecto, Endo and Haemoparasites in Free Range Chicken in the Gomoronzi District in Zimbabwe. Preventive Veterinary Medicine, 54: 213-224. 
[30] Poulsen, J., Permin, A., Hindsho, O., Yelifari, L., Nansen, P. and Bloch, P. (2000). Prevalence and Distribution of Gastrointestinal Helminths and Haemoparasites in young scavenging Chickens in Upper Eastern Region of Ghana, West Africa. Preventive Veterinary Medicine, 45: 237-245.

[31] Ribeiro, S. F., Sebaio, F., Branquinho, F. C. S. and Braga, E. M. (2005). Avian Malaria in Brazilian Passerini birds: Parasitism Detected by Nested PCR using DNA from stained Blood smears. Parasitology, 3: 261-267.

[32] Sabuni, Z. A., Mbuthia, P. G., Maingi, N., Nyaga, P. N., Njagi, L. W., Bebora, L. C. and Michieka, J. N. (2011). Prevalence of haemoparasites infection in indigenous chicken in Eastern Province of Kenya. Livestock Research for Rural Development 23 (11): 2011 . Article \#238.

[33] Sadiq, N. A., Adejinmi, J. O., Adedokun, O. A., Fashanu, S. O., Alimi, A. A. and Sofunmade, Y. T. (2003). Ectoparasites and Haemoparasites of Indigenous Chicken (Gallus domesticus) in Ibadan and Environs. Tropical Veterinarian, (21): 187-191.

[34] Sehgal, R. N. M., Valkiûnas, G., Iezhova, T. A. and Smith, T. B., (2006). Blood Parasites of Chickens in Uganda and Cameroon with Molecular descriptions of Leucocytozoon schoutedeni and Trypanosoma gallinarum. Journal of Parasitology, 92: 1336-1343.

[35] Sehgal, R. N. M., Buermann, W., Harrigan, R. J., Bonneaud, C., Loiseau, C., Chasar, A., Sepil, L., Valkiûnas, G., Iezhova, T. A., Saatchi, S. and Smith, T. B. (2011). Spatially explicit predictions of Blood Parasites in a widely distributed African Rainforest Bird. Proceedings of the Royal Society B, 278: 1025-1033. $7^{\text {th }}$ April 2011; 278 (1708): 1025-1033.

[36] Sehgal, R. N. M. (2015). Manifold Habitat effects on the
Prevalence and diversity of Avian Blood Parasites. International Journal for Parasitology, Parasites and Wildlife, 4: $421-430$

[37] Shadan, H. A. (2013). Prevalence of Blood Parasites in Local Chickens in Qaradagh District, Sulaimani-Iraq. The Iraqi Journal of Veterinary Medicine, 37 (1): 17-21.

[38] Takele, T. and Oli, W. (2011). Uses and Flock Management Practices of Scavenging Chickens in Wolaita Zone of Southern Ethiopia. Tropical Animal Health and Production, 44: $537-544$

[39] Tostes, R., Vashist, U., Scopel, K. K. G., Massard, C. L., Daemon, E. and D'Agosto, M. (2015). Plasmodium spp. and Haemoproteus spp. infection in Birds of the Brazilian Atlantic Forest Detected by Microscopy and Polymerase Chain Reaction. Pesquisa Veterinária Brasileira, 35 (1): 67-74.

[40] Usmana, M., Fabiyia, J. P., Mohammeda, A. A., Merab, U. M., Mahmudaa, A., Alayandea, M. O., Lawala, M. D. and Danmaigoro, A. (2012). Ectoparasites and Haemoparasites of Chickens in Sokoto, Northwestern Nigeria. Scientific Journal of Zoology, 1 (3): 74-78.

[41] Valkiûnas, G. (2005). Avian malaria parasites and other haemosporidia, CRC Press, Boca Raton, Florida, pp. 946.

[42] Valkiûnas, G., Anwar, A. M., Atkinson, C. T., Greiner, E. C., Paperna, I. and Peirce, M. A. (2005). What distinguishes Malaria Parasites from other pigmented Haemosporidians? Trends in Parasitology, 21 (8): 357-358.

[43] Weyuma, H., Singh, H. and Megersa, M. (2015). Studies on Management Practices and Constraints of Back Yard Chicken Production in Selected Rural Areas of Bishoftu. Journal of Veterinary Science and Technology S12: 3. 